Davis, G. H. G., Bisset, K. A. \& Hale, C. M. F. (1955). J.gen. Microbiol. 13, 68-71.

\title{
Correlation between Morphological and Physiological Characters in the Classification of Members of the Genus Lactobacillus
}

\author{
By G. H. G. DAVIS, K. A. BISSET AND C. M. F. HALE \\ Department of Bacteriology, University of Birmingham
}

SUMMARY: Physiologically definable groups within the genus Lactobacillus are morphologically distinct. There are marked differences between homofermentative and heterofermentative strains and between physiological groups within the former.

In recent years little use has been made of morphology in the classification of Lactobacillus. Much emphasis has been placed upon the pleomorphism of members of the genus, a state of affairs which is almost certainly due to inadequate control of growth conditions (cf. Smith, Gottschall \& Wallgren, 1932).

The existence of two main physiological types, homofermentative and heterofermentative is generally recognized, and species within these two types have from time to time been defined, sometimes upon adequate and sometimes upon less adequate criteria. A number of relatively simple tests has been adapted in this laboratory to the purpose of distinguishing certain specific groups, which correspond reasonably closely with those reported by Rogosa, Wiseman, Mitchell, Disraely \& Beaman (1953), Sharpe (1955) and Wheater $(1955 a, b)$. These physiological tests will be the subject of a separate communication.

\section{METHODS}

The morphology and cytology of 221 strains of Lactobacillus were examined. Of these 23 were obtained by courtesy of the National Collection of Industrial Bacteria, Teddington, Middlesex, 3 were isolated from samples of yoghurt, and the remainder from human saliva and carious teeth. All were grown aerobically at $37^{\circ}$ in tomato juice broth of the following formula: tinned tomato juice (filtered) $\mathbf{4 0} \%(\mathrm{v} / \mathrm{v})$, Oxoid peptone $1 \%(\mathrm{w} / \mathrm{v})$, Difco yeast extract $0.5 \%(\mathrm{w} / \mathrm{v})$, sodium acetate $1 \%(\mathrm{w} / \mathrm{v})$, glucose $0.5 \%(\mathrm{w} / \mathrm{v})$, soluble starch $0.05 \%(\mathrm{w} / \mathrm{v})$, Tween $800.1 \%(\mathrm{v} / \mathrm{v})$, salts A $0.5 \%(\mathrm{v} / \mathrm{v})$, salts B $0.5 \%$ $(\mathrm{v} / \mathrm{v}) ; \mathrm{pH}$ value $6 \cdot 8$. The salt solutions $\mathrm{A}$ and $\mathrm{B}$ employed were those of Rogosa et al. (1953).

The cell-form of the organisms was examined in cultures carried in $\frac{1}{4} \mathrm{oz}$. screw-capped (bijou) bottles of this medium after $24 \mathrm{hr}$. incubation. Observations were made upon unstained hanging-drop preparations, Gram-stained films, and preparations stained by Hale's (1953) method to demonstrate cell walls.

Colony structure was examined by means of impression preparations (Bisset, 1938). It was found that the following simplified medium, which closely 
resembles that of Kulp (1927), was best suited to this purpose: tinned tomato juice $40 \%(\mathrm{v} / \mathrm{v})$, Oxoid peptone $1 \%(\mathrm{w} / \mathrm{v})$, Difco yeast extract $1 \%(\mathrm{w} / \mathrm{v})$, glucose $\mathbf{0 . 5} \%(\mathrm{w} / \mathrm{v})$, agar $\mathbf{2 \cdot 5} \%(\mathrm{w} / \mathrm{v}) ; \mathrm{pH}$ value $\mathbf{5 \cdot 5}$.

Impression preparations were made of 12-24 hr. colonies on this medium. Trials were made with the same medium at $\mathrm{pH} \mathbf{7 \cdot 0}$, with $\mathbf{5} \%(\mathrm{v} / \mathrm{v})$ horse-blood nutrient agar, and with the solid medium obtained by adding $2.5 \%(\mathrm{w} / \mathrm{v})$ agar to the more complex tomato juice medium given above. These were unsuitable for the colony impression technique, because the growth tended to be slimy.

\section{RESULTS}

The first general observation was that a high proportion of the homofermentative strains possessed a wreathed, 'Medusa-head' colony, whereas heterofermentative strains had 'smooth' structureless colonies.

The heterofermentative group was physiologically variable, but morphologically, remarkably constant. Out of 113 strains, 88 possessed the morphology shown in Pl. 1, fig. 2. The bacilli consisted of single cells or of two cells separated by a cross-wall. Their colonies were 'smooth' and structureless (Pl. 1, fig. 1). In the remainder the bacilli consisted of two or four cells (Pl. 1, fig. 3), but the colony was equally structureless (Pl. 1, fig. 4).

Despite the physiological heterogeneity of this group, it appears that the first morphological type is characteristic of Lactobacillus fermenti, whereas that with the longer bacilli (Pl. 1, fig. 3) is found in strains previously classified as L. brevis and L. buchneri.

Of the 108 homofermentative isolates, 82 were classifiable as belonging to the Lactobacillus casei-helveticus group. And of these $56(68 \%)$ produced the typical 'Medusa-head' colony (Pl. 2, fig. 6). The remainder gave intermediate or, very occasionally, even 'smooth' colonies. The cell form was alike in all cases, however (Pl. 2, fig. 5), and was characteristic. Although superficially similar to the $L$. brevis type in that both have the four-celled structure commonly seen in septate bacilli, the members of the casei-helveticus group were quite distinct from the former in that they appeared much more slender and flexible, including numerous curved cells in pairs (cf. Orla-Jensen, 1919), and also in their formation of sinuous chains. Even those strains which did not produce really typical 'Medusa-head' colonies, usually appeared in chains when observed in hanging-drop preparations.

The second physiological group of homofermentative lactobacilli, the Lactobacillus acidophilus, L. lactis, L. bulgaricus group, corresponds approximately to the genus Thermobacterium of Orla-Jensen (1919) and was represented by 14 strains. The colony form in all cases was similar (Pl. 2, fig. 7), being the extreme 'Medusa-head' type, appearing almost as a tangled mass. The cell form was also distinctive, and was seen in its most extreme form in strains corresponding to Lactobacillus bulgaricus. The bacilli were very long, with occasional, irregular cross-walls (Pl. 2, fig. 8). The $L$. acidophilus strains varied from this form to chained filaments more like those of the $L$. case $i$ helveticus type. 
Nine strains of Lactobacillus plantarum were exceptional among homofermentative types in that their morphology was characteristic of the majority of heterofermenters (Pl. 1, figs. 1, 2).

\section{DISCUSSION}

The extremes of morphological type in Lactobacillus species are entirely distinct. They vary from short, almost square bacilli in $L$. fermenti, which comprised a very high proportion of heterofermentative strains from saliva, to long filaments with irregular septa in the homofermentative $L$. bulgaricus.

Although the least filamentous of the homofermentative types and the most filamentous of the heterofermentative types may appear almost to converge, their colony forms are for the most part entirely distinct. The 'Medusa-head' colony was so rare as to be almost unknown among the latter, and so common as to be normal among the former, with the exception of one species, Lactobacillus plantarum. The colony structure thus revealed in impression preparations is very constant, and does not necessarily accord with the gross appearance of well-grown colonies in situ, which is exceedingly variable.

Cytological appearances of the commoner recognizable species of Lactobacillus are distinct and provide a valuable taxonomic criterion.

\section{REFERENCES}

Bisset, K. A. (1938). 'The structure of 'rough' and 'smooth' colonies. J. Path. Bact. 47, 223.

HaLe, C. M. F. (1953). The use of phosphomolybdic acid in the demonstration of bacterial cell walls. Lab. Practice, $2,115$.

KULP, W. L. (1927). An agar medium for plating Lactobacillus acidophilus and Lactobacillus bulgaricus. Science, 66, 512.

Orla-Jensen, S. (1919). The Lactic Acid Bacteria. Copenhagen: Andr. Fred. Host. and Son.

Rogosa, M., Wiseman, R. F., Mrtchell, J. A., Disraely, M. N. \& Beaman, A. J. (1953). Species differentiation of oral lactobacilli from man including descriptions of Lactobacillus salivarius nov. spec. and Lactobacillus cellobiosus nov. spec. J. Bact. 65, 681.

Sharpe, M. E. (1955). A serological classification of lactobacilli. J. gen. Microbiol. $12,107$.

Smith, F. L., Gotrschall, R. Y. \& Wallgren, A. B. (1932). A study of the lactobacilli with special reference to the Bacillus acidophilus. J. Lab. clin. Med. 18, 111.

Wheater, D. M. (1955a). The characteristics of Lactobacillus acidophilus and Lactobacillus bulgaricus. J. gen. Microbiol. 12, 123.

Wheater, D. M. (1955b). The characteristics of Lactobacillus plantarum, Lactobacillus helveticus and Lactobacillus casei. J. gen. Microbiol. 12, 133. 
Journal of General Microbiology, Vol. 13, No. 1
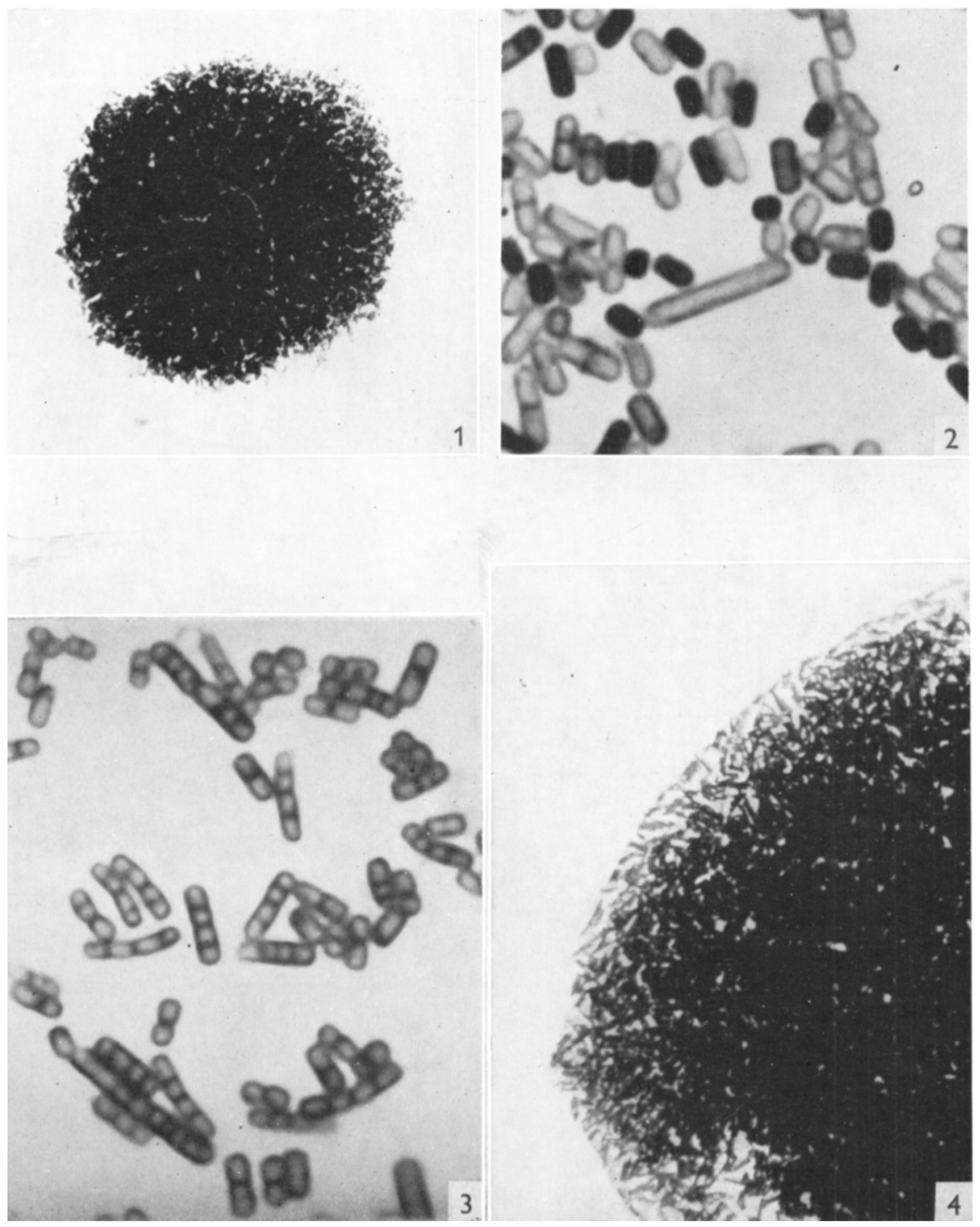

G. H. G. Davis, K. A. Bisset and C. M. F. Hale-Characters of lactobacilli. Plate 1 
Journal of General Microbiology, Vol. 13, No. 1
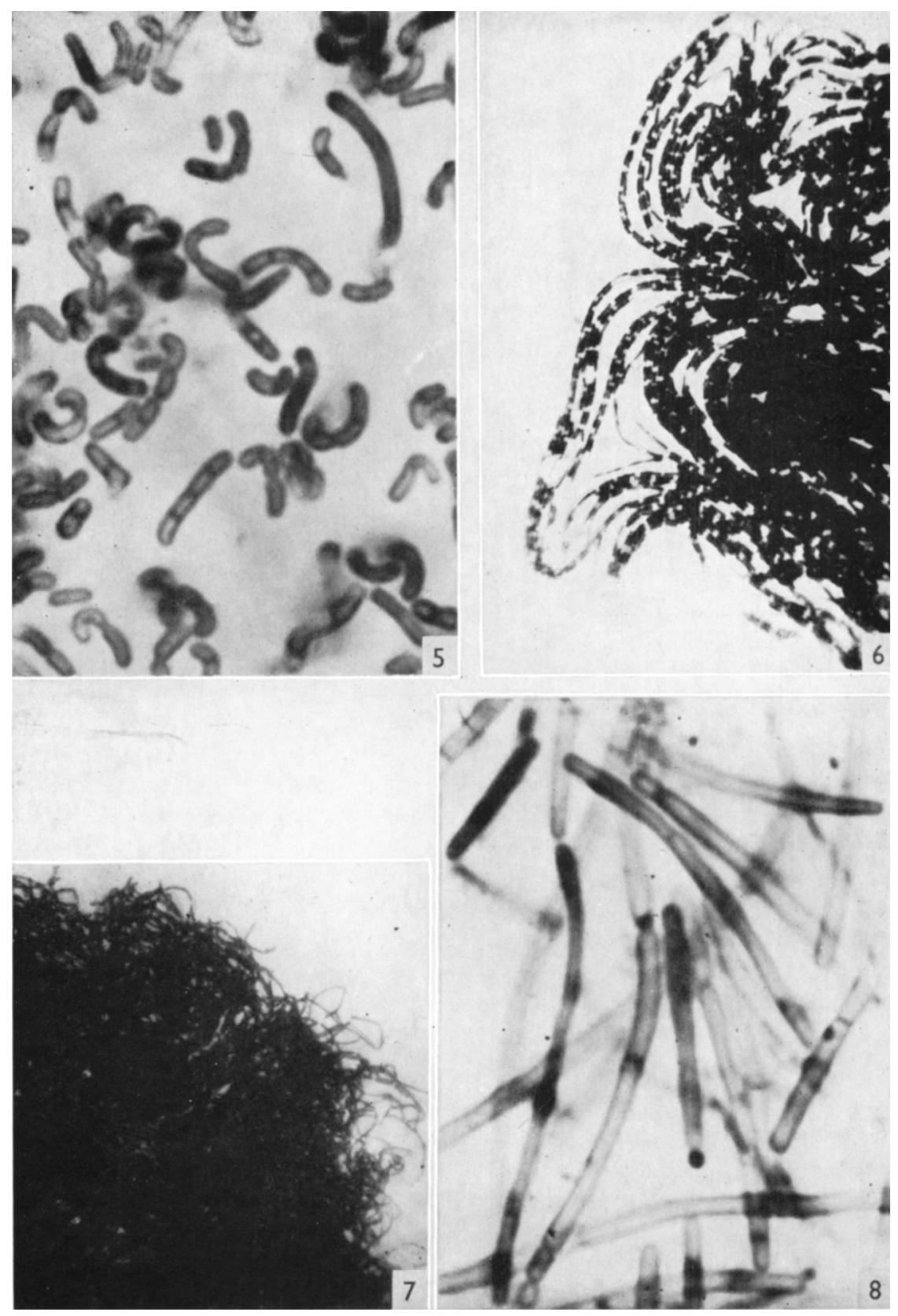

G. H. G. Davis, K. A. Bisset and C. M. F. Hale-Characters of lactobacilli. Plate 2 


\section{EXPLANATION OF PLATES}

Figs. 1, 4, 6 and 7 are impression preparations of entire colonies; $12 \mathrm{hr}$. growth on medium 2; stained by dilute basic fuchsin; photographed at a magnification of $\times 500$, except fig. 1 , at $\times 200$.

Figs. 2, 3, 5 and 8 are stained by Hale's method for cell walls; all at magnification $\times 3000$.

\section{Plate 1}

Figs. 1, 2. Lactobacillus fermenti type, representing the characteristic morphology of heterofermentative strains and also found in strains of L. plantarum. Short bacilli, 'smooth' colony.

Figs. 3, 4. Type of morphology observed in a minority of the heterofermentative strains, probably of the Lactobacillus brevis type and certain strains of $\boldsymbol{L}$. plantarum. Markedly septate bacilli, longer than typical $\boldsymbol{L}$. fermenti type; 'smooth' colony.

\section{Plate 2}

Figs. 5, 6. Lactobacillus casei-helveticus type of morphology, also seen in some strains of L. acidophilus. The typical chain formation is not apparent in Fig. 5, but the curved bacilli are well shown, and the characteristic 'Medusa-head' colony clearly shows the bacilli in chains.

Figs. 7, 8. Lactobacillus bulgaricus and certain strains of L. acidophilus. Extreme filamentous cell-type, with few irregular septa. Tangled 'rough' colony.

(Received 9 December 1954) 